\title{
Effect of Adrenalectomy on the Renal Response to Chloride Depletion in the Rat
}

\author{
R. G. LUKE \\ From the Renal Division, Department of Medicine, University of Kentucky \\ Medical Center, Lexington, Kentucky 40506
}

\begin{abstract}
A B STRACT These experiments were aimed at investigating renal behavior towards chloride, as distinct from sodium, during dietary deprivation of these ions in adrenalectomized rats. Adrenalectomized and shamoperated control rats were maintained on saline for $3 \mathrm{wk}$, then chloride conservation during a very low chloride intake was assessed both with an abundant sodium intake (as buffered sodium phosphate in the drinking water) and after subsequent withdrawal of sodium. When sodium intake was high, there was no difference in chloride conservation between adrenalectomized and control animals, and sodium balance and weight were maintained similarly in both groups. At the same time, both experimental and control rats developed significant hypokalemia and elevation of the plasma bicarbonate levels as compared to other control rats ingesting a normal diet. In another group of adrenalectomized rats sodium phosphate was withdrawn, after normal chloride conservation was observed, and the low-salt diet continued. Negative sodium balance developed and was associated with a negative chloride balance, whereas sham-operated rats continued to conserve sodium and chloride. In further studies during polyuria, both adrenalectomized and control rats developed urinary chloride concentrations of less than $1 \mathrm{meq} / \mathrm{liter}$.

Thus adrenalectomized rats can maintain chloride balance on a low chloride, high sodium intake, in contrast to their inability to conserve sodium on a lowsodium intake. It is concluded that renal tubular reabsorption of chloride in adrenalectomized rats is adequate to establish and maintain very low urinary chloride concentrations, which may imply active chloride transport in the papillary collecting duct despite the absence of adrenocortical hormone. In addition, the typical renal response to chloride deprivation, enhanced loss of potassium and accelerated reabsorption of bicarbonate, is not dependent on adrenocortical hormones.
\end{abstract}

Published in abstract form in 1971. J. Lab. Clin. Med. 78: 1017.

Received for publication 1 February 1974 and in revised form 26 July 1974.

The Journal of Clinical Investigation Volume 54 December 1974·1329-1336

\section{INTRODUCTION}

Active chloride transport in the nephron has been demonstrated in the thick ascending loop of Henle (1), the distal tubule (2), and probably also in the papillary collecting duct (3). Dietary chloride restriction in the rat leads to renal conservation of chloride with low rates of urinary chloride excretion $(4,5)$ and likely active transport of chloride out of the papillary collecting duct (3). The renal chloride conserving mechanism is independent of rates of sodium excretion, phosphate excretion, exposure to $\mathrm{CO}_{2}$, or increased tubular bicarbonate reabsorption (5) and is impaired by severe $\mathrm{K}$ depletion (4) and hydropenia or antidiuretic hormone administration (6). A negative external sodium balance is not necessary to activate the renal chloride conserving mechanism $(4,5)$. Maximum renal conservation of sodium is dependent on aldosterone secretion from the adrenal cortex ( 7 ) but the action, if any, of adrenocortical hormones on the renal chloride conserving process is unknown.

The present studies were performed to determine the effect of bilateral adrenalectomy on renal chloride conservation on the response of the kidney to dietary chloride restriction. The results show normal chloride conservation in adrenalectomized rats maintained on high sodium intakes (as neutral phosphate). Hypokalemia and an elevated plasma bicarbonate also developed in the adrenalectomized rats to the same degree as in appropriate controls which were ingesting the same chloride-free intake.

\section{METHODS}

Male Sprague-Dawley rats weighing 200-400 g (but with matched weights in experimental and control groups in the various experiments) were used. Bilateral adrenalectomy was performed by the dorsal route under pentobarbital anesthesia. Controls were sham-operated. All rats ate chow and drank saline (150 meq/liter) until $3 \mathrm{wk}$ after surgery, when a daily intake of $10 \mathrm{~g}$ of a synthetic low salt diet was substituted for the chow for a further period of 7-10 days. During this latter period, the animals continued to drink saline and became accustomed to individual metabolic cages. Then the response of these adrenalectomized rats to 

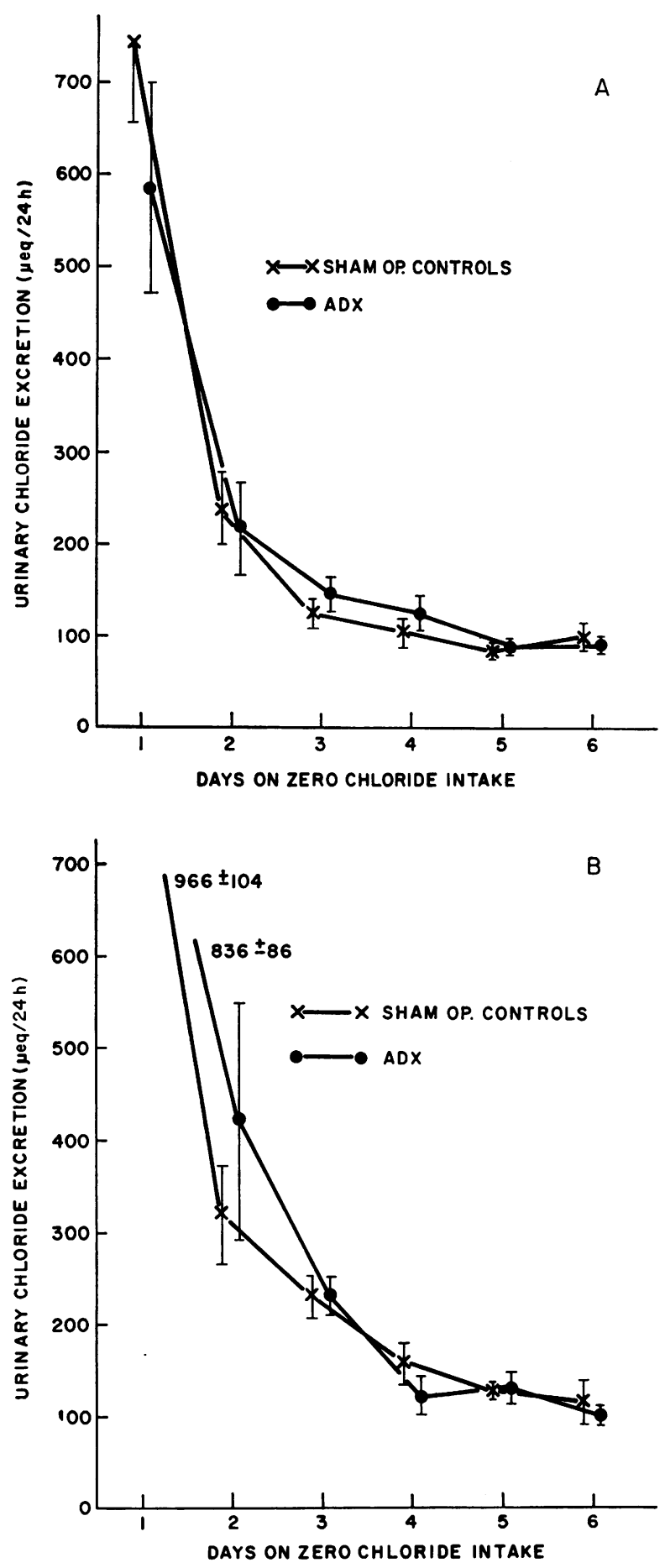

FIGURE 1 Urinary chloride excretion in adrenalectomized and sham-operated control rats for 6 days after withdrawal of chloride intake and while ingesting neutral sodium phosphate $150 \mathrm{meq} /$ liter (A) or $100 \mathrm{meq} / \mathrm{liter}$ (B).

withdrawal of chloride intake was tested by substitution of a buffered sodium phosphate solution ( $\mathrm{pH} 7.4,150 \mathrm{meq} /$ liter) for saline. Preliminary experiments showed that adrenalectomized rats could thrive and gain weight for at least several weeks after substitution of such a chloride-free solution of sodium phosphate for normal saline.

During periods of metabolic balance all rats were given, and ate, $10 \mathrm{~g}$ daily of the low-salt diet. The synthetic lowsalt diet (ICN Nutritional Biochemicals Div., International Chemical \& Nuclear Corp., Cleveland, Ohio) contained, by analysis after nitric acid extraction, less than $10 \mu \mathrm{eq}$ chloride and 1,400 $\mu$ eq potassium per $10 \mathrm{~g}$ diet. Metabolic balances were performed in individual cages with screens to separate urine from feces. Water bottles containing the electrolyte solutions were arranged so that any leak would be collected in the urine. Amounts of ingested sodium chloride or sodium phosphate were measured daily by weight.

Exp. 1. Metabolic balance was begun immediately after substitution of sodium phosphate for sodium chloride and continued for 6 days. At the end of this period animals were sacrificed by exsanguination from the abdominal aorta under pentobarbital anesthesia $(50 \mathrm{mg} / \mathrm{kg})$. At sacrifice, complete bilateral adrenalectomy was confirmed. Blood urea nitrogen (BUN), ${ }^{1}$ plasma sodium, potassium, chloride, and arterial $\mathrm{pH}, \mathrm{PCO}_{2}$, and bicarbonate were measured on the arterial blood obtained at sacrifice. These measurements were also made on a group of normal rats ingesting regular rat chow and water.

In order to observe the effects on chloride conservation of two different concentrations of sodium phosphate, and of ingestion of isotonic and hypotonic solutions, two separate experiments were performed; in exp. 1A animals drank a solution of neutral sodium phosphate $150 \mathrm{meq} / \mathrm{liter}$ (a buffered solution of $\mathrm{NaH}_{2} \mathrm{PO}_{4}$ and $\mathrm{Na}_{2} \mathrm{HPO}_{4}$ ) and in exp. 1B sodium phosphate $100 \mathrm{meq} / \mathrm{liter}$

Exp. 2. The protocol was identical to that of exp. 1A except that, after a 4-day period of chloride conservation on the low-salt diet and sodium phosphate, a further 4-day period of metabolic balance was performed during withdrawal of sodium by substitution of demineralized water for the sodium phosphate solution. At the end of this experiment only plasma electrolytes were measured.

Exp. 3. The protocol was again identical to $1 \mathrm{~A}$ except that, after 6 days on the low-salt diet and sodium phosphate $150 \mathrm{meq} / \mathrm{liter}$, polyuria was induced in both adrenalectomized and sham-operated control rats by substitution of sodium phosphate in $5 \%$ dextrose $(50 \mathrm{meq} / \mathrm{liter})$ for the regular sodium phosphate solution. The aim of the experiment was to determine the ability of the distal nephron to lower urinary chloride concentration during polyuria. No measurements were made on plasma.

BUN was measured by the method of Crocker (8), plasma and urinary sodium by an I1 flame photometer (Instrumentation Laboratory, Inc., Lexington, Mass.) with internal lithium standard, and plasma and urinary chloride by a Buchler chloridometer (Buchler Instruments Div. Nuclear-Chicago Corp., Fort Lee, N. J.). Arterial pH and $\mathrm{PCO}_{2}$ were measured by a blood gas analyzer with directreading electrodes (BMS 3 blood microsystem and PHM 71 acid-base analyzer, Radiometer, Copenhagen) and actual plasma bicarbonate was calculated by using a SiggaardAnderson normogram.

\section{RESULTS}

Experiment 1 (Tables I-III; Fig. 1). Results of balance data for exps. $1 \mathrm{~A}$ and $1 \mathrm{~B}$ are discussed sepa-

${ }^{1}$ Abbreviations used in this paper: BUN, blood urea nitrogen; GFR, glomerular filtration rate. 
rately because of the different concentrations of sodium in the drinking solution (150 and $100 \mathrm{meq} / \mathrm{liter}$, respectively), but results of arterial blood electrolytes and acid-base status are combined since they were not different. After exposure to a low-chloride intake, renal chloride conservation was very similar in both adrenalectomized and sham-operated rats in both exps. 1A and 1B (Fig. 1 and Table I). Although sodium intake in adrenalectomized animals was less than control in exp. $1 \mathrm{~B}$, sodium balance remained positive in experimental and control animals in both exps. 1A and 1B. Weight was maintained over the 6-day period of chloride conservation but cumulative potassium balance was negative in both groups (Table II).

Plasma electrolyte and acid-base status at the end of the 6-day period of zero chloride intake is shown in Table III. There was no difference in plasma levels between the adrenalectomized and sham-operated groups, but both of these groups had a significantly lower plasma potassium and a higher arterial $\mathrm{pH}$ and plasma bicarbonate than rats which ingested water and normal chow and in which measurements were performed by the same techniques (Table III).

Exp. 2 (Table IV; Figs. 2 and 3). During ingestion of sodium phosphate, as in exp. 1, chloride excretion during dietary chloride restriction was not different between sham-operated and adrenalectomized rats. However, when sodium intake was restricted, a negarive sodium balance was associated with urinary chloride loss in the adrenalectomized, but not in the sham-operated control group, which conserved sodium normally and continued to conserve chloride (Fig. 2, Table IV). Urinary chloride concentration in the experimental and
TABLE I

Comparison of Chloride Conservation between Adrenalectomized and Sham-Operated Rats

\begin{tabular}{ccc}
\hline$n$ & 6 day $\mathrm{Cl}^{*}$ & Ucı day $6 \ddagger$ \\
\hline$\mu e q$ & meq/liter
\end{tabular}

Exp. 1A (drinking sodium phosphate $150 \mathrm{meq} / \mathrm{liter}$ )

$\begin{array}{cccc}\text { Sham } & 8 & 1,390 \pm 117 \S & 3.3 \pm 0.6 \\ \text { Adx } & 6 & 1,248 \pm 152 & 3.9+0.5 \\ t \text { test } & & \text { NS } & \text { NS }\end{array}$

Expt. 1B (drinking sodium phosphate $100 \mathrm{meq} /$ liter)

$\begin{array}{cccc}\text { Sham } & 9 & 1,916 \pm 137 & 2.6 \pm 0.3 \\ \text { Adx } & 7 & 1,849 \pm 198 & 2.9 \pm 0.7 \\ t \text { test } & & \text { NS } & \text { NS }\end{array}$

* Cumulative 6 day chloride excretion during zero chloride intake.

$\ddagger$ Urinary chloride concentration on 6 th day of zero chloride intake.

$\S$ Mean \pm SEM.

the control group on day 4 of chloride conservation did not differ, but there was a significantly higher urinary chloride concentration on day 8 in the adrenalectomized group after sodium restriction (Fig. $3, P<0.05$ ). Urinary sodium concentration on day 8 in the two groups was also higher in the adrenalectomized as compared to control rats (Fig. 3, $P<0.001$ ).

In the adrenalectomized group, potassium balance was not different during sodium phosphate ingestion but became significantly more positive during sodium restriction (Table IV). Plasma potassium was also higher in this group.

TABLE II

Sodium and Potassium Balance and Change in Weight in Adrenalectomized and Sham-Operated Rats on Zero Chloride Intake

\begin{tabular}{|c|c|c|c|c|c|c|}
\hline & $n$ & $\begin{array}{c}\text { Initial } \\
\text { wt* }^{*}\end{array}$ & $\begin{array}{c}\text { Wt } \\
\text { changeł }\end{array}$ & $\begin{array}{c}\text { Daily } \mathrm{Na} \\
\text { intake }\end{array}$ & $\begin{array}{l}\text { Daily Na } \\
\text { balance§ }\end{array}$ & $\begin{array}{l}\text { Daily K } \\
\text { balance§ }\end{array}$ \\
\hline & & $g$ & $g$ & $\mu e q$ & $\mu e q$ & $\mu e q$ \\
\hline \multicolumn{7}{|c|}{ Exp. 1A (drinking sodium phosphate 150 meq/liter) } \\
\hline $\begin{array}{l}\text { Sham } \\
\text { Adx } \\
t \text { test }\end{array}$ & $\begin{array}{l}8 \\
6\end{array}$ & $\begin{array}{c}334 \pm 15 \| \\
325 \pm 21 \\
\text { NS }\end{array}$ & $\begin{array}{c}-6 \pm 1 \\
-5 \pm 2 \\
\mathrm{NS}\end{array}$ & $\begin{array}{c}5,885 \pm 595 \\
5,927 \pm 761 \\
\text { NS }\end{array}$ & $\begin{array}{c}+319 \pm 370 \\
+314 \pm 239 \\
\mathrm{NS}\end{array}$ & $\begin{array}{c}-48 \pm 82 \\
-57 \pm 70 \\
N S\end{array}$ \\
\hline \multicolumn{7}{|c|}{ Exp. 1B (drinking sodium phosphate $100 \mathrm{meq} /$ liter) } \\
\hline $\begin{array}{l}\text { Sham } \\
\text { Adx } \\
t \text { test }\end{array}$ & $\begin{array}{l}9 \\
7\end{array}$ & $\begin{array}{c}243 \pm 7 \\
223 \pm 13 \\
\text { NS }\end{array}$ & $\begin{array}{c}+7 \pm 12 \\
+9 \pm 7 \\
\text { NS }\end{array}$ & $\begin{array}{c}5,761 \pm 248 \\
4,824 \pm 191 \\
P<0.01\end{array}$ & $\begin{array}{c}+774 \pm 218 \\
+806 \pm 228 \\
\text { NS }\end{array}$ & $\begin{array}{c}-593 \pm 146 \\
-287 \pm 235 \\
\mathrm{NS}\end{array}$ \\
\hline
\end{tabular}

* At start of zero chloride intake.

$¥$ Weight change during 6 days of zero chloride intake.

$\$$ Mean daily intake and balance during 6 days of zero chloride intake. $\mathrm{K}$ intake was equal in all rats $(1,400 \mu \mathrm{eq} / 10 \mathrm{~g}$ diet $)$.

$\|$ Mean \pm SEM. 
TABLE III

Plasma Electrolytes, Bun, and Arterial pH in Adrenalectomized, Sham-Operated (Exp. $1 A$ and 1B), and Normal Rats

\begin{tabular}{|c|c|c|c|c|c|c|c|c|}
\hline & $n$ & BUN & $\mathrm{Na}$ & $\mathbf{K}$ & $\mathrm{Cl}$ & $\mathrm{H}^{+}(\mathrm{pH})$ & Arterial $\mathrm{Pco}_{2}$ & $\mathrm{HCO}_{3}$ \\
\hline & & $m g / 100 m l$ & & meq/liter & & nmol/liter & $m m \mathrm{Hg}$ & mmol/liter \\
\hline Sham-operated & 17 & $15.4 \pm 0.9^{*}$ & $142.0 \pm 0.6$ & $2.9 \pm 0.2 \ddagger$ & $101.1 \pm 0.8 \S$ & $\begin{array}{c}36.9 \pm 2.6 \ddagger \\
(7.43)\end{array}$ & $39.6 \pm 1.2$ & $26.2 \pm 1.0 \ddagger$ \\
\hline Ad $\mathbf{x}$ & 13 & $16.8 \pm 1.2$ & $141.6 \pm 0.6$ & $2.7 \pm 0.2 \ddagger$ & $100.8 \pm 1.7$ & $\begin{array}{c}38.1 \pm 1.3 \ddagger \\
\quad(7.42)\end{array}$ & $37.7 \pm 1.1 \|$ & $25.0 \pm 1.3 \ddagger$ \\
\hline Normal & 12 & $16.0 \pm 0.7$ & $140.0 \pm 0.8$ & $4.6 \pm 0.1$ & $104.5 \pm 0.6$ & $\begin{array}{c}58.8 \pm 2.2 \\
(7.23)\end{array}$ & $42.0 \pm 1.5$ & $17.7 \pm 0.6$ \\
\hline
\end{tabular}

* Mean \pm SEM. There were no significant differences between adrenalectomized (Adx) and sham-operated rats. If not indicated by symbol then no significant difference between either group and normal rats was found.

$\ddagger P<0.001$ as compared to normal rats.

$\S P<0.01$ as compared to normal rats.

$\| P<0.05$ as compared to normal rats.

Tा Eating chow and drinking water only.

Exp. 3 (Table $V$ ). Adrenalectomized rats ingested smaller amounts of fluid and excreted smaller urine volumes than sham-operated controls (Table V). Urinary chloride concentrations during polyuria were lower in the adrenalectomized rats. Because of the lower urinary volumes and lower urinary chloride concentrations, chloride excretion was less in the adrenalectomized rats (Table V).

\section{DISCUSSION}

Failure to reabsorb about $2 \%$ of the filtered sodium load is the main functionally important defect in adrenalec-

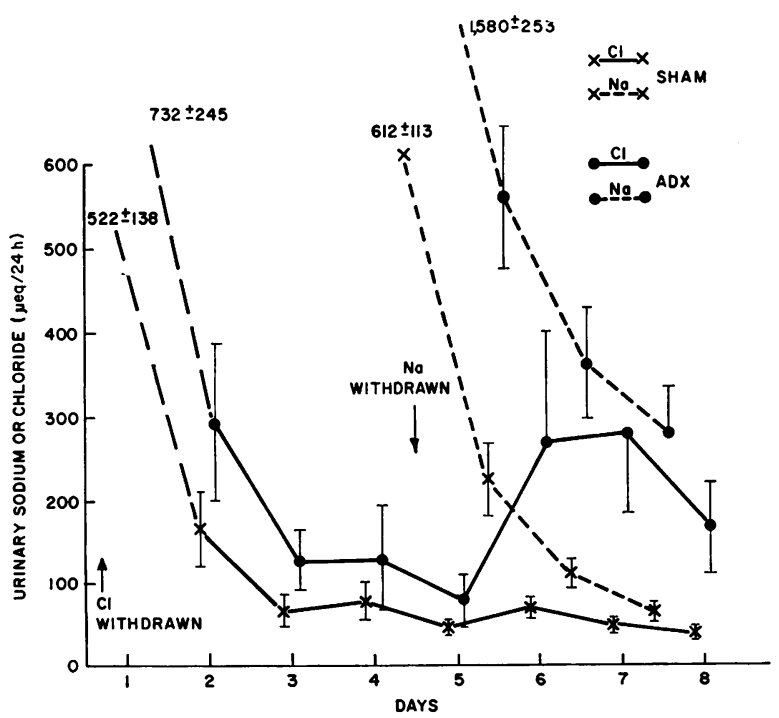

FIGURE 2 Urinary chloride excretion during ingestion of neutral sodium phosphate (chloride restriction, days 1-4) and after withdrawal of sodium phosphate (days 5-8, chloride and sodium restriction) in adrenalectomized and sham-operated control rats. tomized animals (9). While there are abnormalities of sodium handling in the proximal tubule, fractional reabsorption of sodium at that site is not decreased $(10,11)$, and negative sodium balance in adrenalectomized rats on low sodium intakes can be attributed to impaired absorption in the distal convoluted tubules and collecting ducts (10). Aldosterone increases the active transport capacity for sodium in the collecting ducts and diminishes their permeability to passive back diffusion (12, 13).

In normal rats restoration of electrolyte balance for sodium and chloride after elimination of these ions from the diet is dependent upon absorption by the papillary collecting duct of almost all of the filtered load of sodium and chloride reaching that site $(3,14)$. During this process, steep transepithelial sodium and chloride concentration gradients are created between the urine and the papillary interstitium. Since the measured collecting duct transtubular potential is uniformly negative, sodium transport at this site is occurring against the electrochemical gradient and hence involves active transport. Diezi, Michoud, Aceves, and Giebisch have recently concluded, from consideration of the electrochemical potential gradient during micropuncture studies of the papillary collecting duct, that active chloride transport also "virtually certainly" occurs at that site at low rates of urinary chloride excretion. They discuss their own (in the rat) and previous (in the rat and golden hamster) measurements of papillary collecting duct transtubular potential differences, which have been in the range of -10 to $-34 \mathrm{mV}$. The higher value in this range was found during sodium sulphate diuresis, and, even in these circumstances, movement of chloride out of the collecting duct could not be explained on a basis of passive transport (15). The mean ratio of vasa recta to collecting duct chloride concentration 
TABLE IV

(Exp. 2) Sodium, Potassium, and Chloride Excretion and Plasma Electrolytes in Adrenalectomized and Sham-Operated Rats during Chloride Restriction with Ingestion of High Sodium and with Zero Sodium Intake

\begin{tabular}{|c|c|c|c|c|c|c|c|c|}
\hline & \multirow[b]{2}{*}{$n$} & \multicolumn{2}{|c|}{$\mathrm{Ucl}^{*}$} & \multirow{2}{*}{\multicolumn{2}{|c|}{ 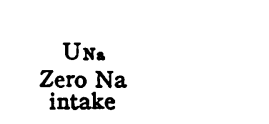 }} & \multicolumn{2}{|c|}{$\mathrm{K}$ balance } & \multirow{2}{*}{$\begin{array}{c}t \text { test } \\
\text { on mean } \\
\text { difference }\end{array}$} \\
\hline & & $\underset{\substack{\text { High Na } \\
\text { intake }}}{\text { Hal }}$ & $\begin{array}{c}\text { Zero } \mathrm{Na} \\
\text { intake }\end{array}$ & & & $\underset{\substack{\text { High Na } \\
\text { intake }}}{\text { Hial }}$ & $\begin{array}{c}\text { Zero } \mathrm{Na} \\
\text { intake }\end{array}$ & \\
\hline & & \multicolumn{2}{|c|}{$\mu e q / 4$ days } & \multicolumn{2}{|c|}{ req/4 days } & \multicolumn{2}{|c|}{$\mu e q / 24 h$} & \\
\hline $\begin{array}{l}\text { Sham } \\
\text { Adx } \\
t \text { test }\end{array}$ & $\begin{array}{l}5 \\
5\end{array}$ & $\begin{array}{c}826 \pm 121 \S \\
1,279 \pm 165 \\
N S\end{array}$ & $\begin{array}{l}189 \pm 30 \\
787 \pm 210 \\
P<0.025\end{array}$ & & $\begin{array}{l}116 \\
351 \\
005\end{array}$ & $\begin{array}{c}+10 \pm 80 \\
-48 \pm 130 \\
\text { NS }\end{array}$ & $\begin{array}{l}+108 \pm 50 \\
+300 \pm 54 \\
P<0.05\end{array}$ & $\begin{array}{c}\text { NS } \\
P<0.01\end{array}$ \\
\hline $\begin{array}{l}\text { Sham } \\
\text { Adx } \\
t \text { test }\end{array}$ & $\begin{array}{l}5 \\
5\end{array}$ & & $\begin{array}{r}\mathrm{Pla} \\
14 \\
13\end{array}$ & & $\begin{array}{c}\text { Plasma K } \\
4.8 \pm 0.1 \\
6.8 \pm 0.8 \\
\text { NS }\end{array}$ & $\begin{array}{r}\text { Plas } \\
101 . \\
97 .\end{array}$ & $\begin{aligned} & \mathrm{Cl} \\
= & 0.9 \\
= & 2.3\end{aligned}$ & \\
\hline
\end{tabular}

* Cumulative 4 day chloride excretion during chloride restriction while ingesting sodium phosphate and in a subsequent 4-day period while ingesting demineralized water.

$\ddagger \mathrm{K}$ intake was constant throughout $(1,400 \mu \mathrm{eq} / \mathrm{day})$.

$\S$ Mean \pm SEM.

$\|$ At end of experiment.

in the studies of Diezi et al. was 8.4 to 1 (3). In the present experiments, the ratio of plasma to urinary chloride was approximately 30 to 1 in exps. $1 \mathrm{~A}$ and $1 \mathrm{~B}$ and considerably higher than this in the polyuria experiments, in which mean urinary chloride concentration was $0.3 \mathrm{meq} / \mathrm{liter}$ in the adrenalectomized rats. Thus, while these balance experiments can justify no conclusions about the nature of the transport process

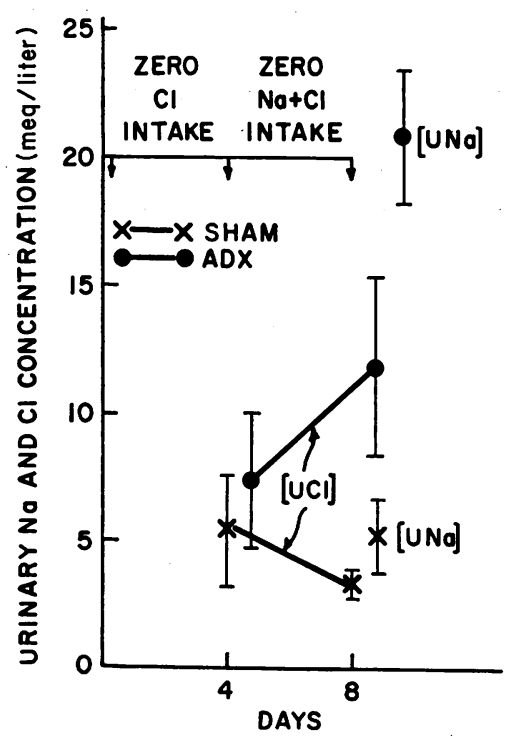

FIGURE 3 Urinary sodium and chloride concentrations at the end of chloride restriction while ingesting neutral sodium phosphate (day 4) and after chloride and sodium restriction (day 8) in adrenalectomized and sham-operated control rats. underlying chloride absorption in the collecting duct in adrenalectomized rats, it seems likely, on the basis of these previous observations, that active chloride transport in the collecting duct is taking place in the absence of mineralocorticoid hormone. Cortney has previously shown that proximal and distal tubular fluid-to-plasma and urinary-to-plasma chloride ratios in adrenalectomized rats ingesting $1 \%$ sodium chloride were not different from control rats (10). The present study certainly demonstrates that adrenalectomized rats can, in response to selective dietary chloride restriction, establish and maintain low urinary chloride concentrations so that chloride balance is maintained; this contrasts with the inability of the adrenalectomized rat to establish adequately low urinary sodium concentrations to maintain sodium balance in response to dietary sodium restriction in similar experimental circumstances.

The absence of a direct effect of mineralocorticoid hormone on renal chloride conservation is also illustrated

TABLE V

(Exp. 3) Effect of Polyuria on Urinary Chloride Concentration in Adrenalectomized and Sham-operated Rats

\begin{tabular}{ccccc}
\hline & $n$ & Ucl & UV & $\begin{array}{r}\text { Chloride } \\
\text { excretion }\end{array}$ \\
\hline Sham & $9^{*}$ & meq/liter & $m l / 24 h$ & meq $/ 24 h$ \\
Adx & 9 & $0.6 \pm 0.07 \ddagger$ & $94 \pm 4$ & $55 \pm 5$ \\
$t$ test & & $P<0.08$ & $45 \pm 5$ & $13 \pm 2$ \\
& & $P<0.02$ & $P<0.001$ & $P<0.001$
\end{tabular}

* Three rats for 3 days.

$\ddagger$ Mean \pm SEM. 
by previous observations that the administration of desoxycorticosterone acetate to rats conserving urinary chloride on a low-chloride diet, which contained a normal sodium content as sodium bicarbonate, was associated with significant sodium retention but no change in chloride excretion (6).

Glomerular filtration rate (GFR) was not measured in these experiments but the similarly positive sodium balance, weight gain, and BUN in rats ingesting an identical diet all suggest that reduction of GFR in the adrenalectomized rats on sodium phosphate did not contribute to the reduction of chloride excretion in these animals. Although GFR has been reduced in adrenalectomized rats $(10,16)$, it may be normal in rats maintained on saline (17). Even if delivery of chloride to the distal nephron was reduced by a diminished GFR in the adrenalectomized group, the distal nephron still was capable of creating and maintaining the same low urinary chloride concentration as in control rats.

The effect of ingestion of phosphate, as a relatively unreabsorbable anion, on the chloride conserving process must be considered. In previous experiments from this laboratory we have demonstrated in normal rats that ingestion of phosphate-containing solutions in the range of $25-100 \mathrm{meq} / \mathrm{liter}$ has no effect on the efficiency of renal chloride conservation during dietary chloride restriction, as compared to conservation on a low-salt diet or on a low-chloride diet containing sodium bicarbonate $(4,5,18)$. However, bromide, thiocyanate, and nitrate did impair chloride conservation, and this effect was not correlated with the relative reabsorbability of the anions studied (18).

In the adrenalectomized rats, chloride conservation after deprivation of both sodium and chloride became abnormal and was associated with negative chloride balance. In the normal rat, chloride balance is established, and a steady-state level of low urinary chloride excretion is achieved, by the 4th or 5th day after dietary chloride restriction (4), as in the present exps. $1 \mathrm{~A}$ and $1 \mathrm{~B}$. In these circumstances renal chloride conservation is not affected by rates of sodium excretion (5), or by whether sodium restriction is imposed before, or simultaneously with chloride restriction (unpublished observations). Thus the sodium and chloride conserving processes in the distal nephron may be independently activated. In adrenalectomized rats any active component of sodium transport out of the collecting duct is absent or impaired $(12,13)$. Nevertheless, chloride conservation after selective dietary chloride deprivation remains normal since net chloride reabsorption can be accompanied by an equivalent reabsorption of sodium, which is available in abundance and at high concentrations in the distal nephron because of the high intakes of sodium phosphate. In contrast, when the adrenalectomized rat is also subjected to sodium restriction, the collecting duct is incapable of reabsorbing sodium against steep concentration gradients, increased passive back diffusion of sodium into the collecting duct lumen takes place $(12,13)$, and natriuresis and negative sodium balance ensues. The chloride transport system in these circumstances would inevitably be impaired for secondary electrochemical reasons.

The significantly lower urinary chloride concentrations in the adrenalectomized rats during polyuria are of interest. The lower intakes of dextrose water, and of the hypotonic sodium phosphate solution employed in exp. $1 \mathrm{~B}$, in the adrenalectomized animals as compared to controls are probably secondary to the recognized inability of such animals to excrete a water load (19). A lower urinary volume might be expected to be associated with a higher urinary concentration of chloride in the adrenalectomized rats, rather than the contrary finding. This apparently paradoxical observation in the adrenalectomized rat may relate to the lower papillary sodium concentration (and presumably chloride concentrations) in these rats $(20)$, since there would then be less passive back diffusion of chloride into the collecting duct. Similarly, sodium conservation after dietary sodium restriction in rats with diabetes insipidus and low papillary sodium concentrations is more efficient than in normal controls (21).

Effect of adrenalectomy on renal response to chloride deprivation. Aldosterone stimulates sodium-hydrogen and sodium-potassium exchange together with sodium chloride absorption (16), and adrenal insufficiency is commonly associated with metabolic acidosis and renal potassium retention. Adrenalectomized rats show a markedly impaired net acid excretion in response to metabolic acidosis with diminished titratable acid and ammonium excretion (22). Kurtzman, White, and Rogers (23) attributed acidosis in adrenalectomized dogs maintained on glucocorticoids to a defect in dista! tubular bicarbonate reabsorption. Adrenalectomized rats breathing $8 \% \mathrm{CO}_{2}$ in air for $24 \mathrm{~h}$ increased plasma bicarbonate normally, as compared to controls, without an increase in net acid excretion (24); thus, the adrenalectomized rat can increase renal tubular reabsorption of bicarbonate in response to respiratory acidosis but is unable to increase net acid excretion. Urinary net acid excretion was not measured in these experiments, but the elevation of plasma bicarbonate in the adrenalectomized and control rats, as compared to normal rats, must mean enhanced renal tubular secretion of hydrogen ion (reabsorption of bicarbonate). As discussed by Seldin and Rector (25), maintenance of a metabolic alkalosis implies an elevated tubular reabsorption of bicarbonate but not necessarily any change in net acid excretion. Thus, the adrenalectomized rat, like the

\section{4 \\ R. G. Luke}


normal rat, can increase tubular secretion of hydrogen ion in response to respiratory acidosis or to selective dietary chloride restriction.

Schwartz has summarized his extensive experimental evidence that chloride depletion leads to enhanced sodium-hydrogen and sodium-potassium exchange in the distal nephron (26). His group has also shown that metabolic alkalosis associated with selective chloride depletion in man is not dependent on increased aldosterone secretion rates (27). While Rector has stated that, for chloride depletion to produce metabolic alkalosis, reabsorption of sodium must be simulated to such an intense degree that the urine is virtually sodium free (28), an elevation of plasma bicarbonate has been observed in normal rats which were on a low-chloride diet, ingested neutral sodium phosphate, and which maintained sodium balance and relatively high levels of urinary sodium excretion (5). The maintained sodium balance and normal BUN, during the ingestion of sodium phosphate without chloride, in the present studies suggests that chloride restriction alone is associated with sufficient acceleration of tubular sodium-hydrogen ion exchange (sodium bicarbonate reabsorption) to maintain sodium balance and elevate tubular reabsorption of bicarbonate, even in the absence of mineralocorticoid hormone.

Of additional interest is the significant hypokalemia in the adrenalectomized rats on the low-chloride, normalpotassium diet. Giebisch has stated that "an adequate level of circulating adrenal mineralocorticoid is necessary for maintenance of normal secretory capacity of potassium ions along the terminal nephron segment" (29). These experiments suggest that dietary chloride restriction, in the presence of an abundant sodium intake with an unreabsorbable anion, is sufficient to accelerate potassium secretion, and thus to lead to a negative potassium balance and hypokalemia, despite the absence of mineralocorticoid.

Thus both renal conservation of chloride and the characteristic renal response to chloride restriction or depletion, enhanced bicarbonate reabsorption and enhanced tubular potassium secretion, are not dependent on adrenocortical hormone. The mechanism underlying, and the nature of the stimulus to the probably active chloride transport process in the distal nephron which leads to renal chloride conservation remain unknown.

\section{ACKNOWLEDGMENTS}

This work was supported by grant no. AM 13859 from the National Institutes of Health.

\section{REFERENCES}

1. Rocha, A. S., and J. P. Kokko. 1973. Sodium chloride and water transport in the medullary thick ascending limb of Henle. Evidence for active chloride transport. J. Clin. Invest. 52: 612-623.
2. Rector, F. C., Jr., and J. R. Clapp. 1962. Evidence for active chloride reabsorption in the distal renal tubule of the rat. J. Clin. Invest. 41: 101-107.

3. Diezi, J., P. Michoud, J. Aceves, and G. Giebisch. 1973. Micropuncture study of electrolyte transport across papillary collecting duct of the rat. Am. J. Physiol. 224 : 623-634.

4. Luke, R. G., and H. Levitin. 1967. Impaired renal conservation of chloride and the acid-base changes associated with potassium depletion in the rat. Clin. Sci $(O x f) .32:. 511-526$.

5. Luke, R. G., Y. Warren, M. Kashgarian, and H. Levitin. 1970. Effects of chloride restriction and depletion on acid-base balance and chloride conservation in the rat. Clin. Sci. (Oxf.). 38: 385-396.

6. Luke, R. G. 1973. Natriuresis and chloruresis during hydropenia in the rat. Am. J. Physiol. 224: 13-20.

7. Pitts, R. F. 1968. Physiology of the Kidney and Body Fluids. Year Book Medical Publishers, Inc., Chicago. 2nd edition. 219.

8. Crocker, C. L. 1967. Rapid determination of urea nitrogen in serum or plasma without deproteinization. Am. J. Med Technol. 33: 361-365.

9. Roemmelt, J. C., O. W. Sartorius, and R. F. Pitts. 1949. Excretion and reabsorption of sodium and water in the adrenalectomized dog. Am. J. Physiol. 159: 124 136.

10. Cortney, M. A. 1969. Renal tubular transfer of water and electrolytes in adrenalectomized rats. Am. J. Physiol. 216: $589-598$.

11. Hierholzer, K., and H. Stolte. 1969. The proximal and distal tubular action of adrenal steroids on $\mathrm{Na}$ reabsorption. Nephron. 6: 188-204.

12. Uhlich, E., C. A. Baldamus, and K. J. Ullrich. 1969. The effect of aldosterone on sodium transport in the collecting ducts of the mammalian kidney. Pflïgers Arch. Eur. J. Physiol. 308: 111-126.

13. Uhlich, E., R. Halbach, and K. J. Ullrich. 1970. Influence of aldosterone on ${ }^{24} \mathrm{Na}$-efflux in collecting ducts of rats. Pflügers Arch. Eur. J. Physiol. 320: 261-264.

14. Malnic, G., M. Mello-Aires, and F. Lacaz-Vieira. 1970. Chloride excretion in nephrons of rat kidney during alterations of acid-base equilibrium. Am. J. Physiol. 218: $20-26$.

15. Laurence, R., and D. J. Marsh. 1971. Effect of diuretic states on hamster collecting duct electrical potential differences. Am. J. Physiol. 220: 1610-1616.

16. Giebisch, G. 1962. Kidney, water and electrolytes. Annu. Rev. Physiol. 24 : 357-420.

17. Lotspeich, W. D. 1949. The effect of adrenalectomy on the renal tubular reabsorption of water in the rat. Endocrinology. 44 : 314-316.

18. Luke, R. 1970. Effect of other monovalent anions on the renal conservation of chloride. J. Lab. Clin. Med. 76: 1039. (Abstr.)

19. Green, H. H., A. R. Harrington, and H. Valtin. 1970. On the role of antidiuretic hormone in the inhibition of acute water diuresis in adrenal insufficiency and the effects of gluco- and mineralocorticoids in reversing the inhibition. J. Clin. Invest. 49: 1724-1736.

20. Sigler, M. H., J. N. Forrest, Jr., and J. R. Elkinton. 1965. Renal concentrating ability in the adrenalectomized rat. Clin. Sci. (Oxf.). 28: 29-37.

21. Harrington, A. R., and R. E. Rieselbach. 1970. Na conservation in rats with reduced medullary osmotic gradient due to diabetes insipidus. Am. J. Physiol. 219: 384-386. 
22. Sartorius, O. W., D. Calhoon, and R. F. Pitts. 1953. Studies on the interrelationships of the adrenal cortex and renal ammonia excretion by the rat. Endocrinology. 52: 256-265.

23. Kurtzman, N. A., M. G. White, and P. W. Rogers. 1971. Aldosterone deficiency and renal bicarbonate reabsorption. J. Lab. Clin. Med. 77: 931-940.

24. Luke, R. G., and H. Levitin. 1966. The renal and electrolyte response to respiratory acidosis in the adrenalectomized rat. Yale J. Biol. Med. 39: 27-37.

25. Seldin, D. W., and F. C. Rector, Jr. 1972. The generation and maintenance of metabolic alkalosis. Kidney Int. 1 : 306-321.

26. Schwartz, W. B., C. Van Ypersele De Strihou, and
J. P. Kassirer. 1968. Role of anions in metabolic alkalosis, and potassium deficiency. N. Engl. J. Med. 279: 630-639.

27. Kassirer, J. P., F. M. Appleton, J. A. Chazan, and W. B. Schwartz. 1967. Aldosterone in metabolic alkalosis. J. Clin. Invest. 46: 1558-1571.

28. Rector, F. C., Jr. 1971. Renal secretion of hydrogen. In The Kidney: Morphology, Biochemistry, Physiology. C. Rouiller, and A. F. Muller, editors. Academic Press, Inc., New York. 3: 209-252.

29. Giebisch, G. 1971. Renal potassium excretion. In The Kidney: Morphology, Biochemistry, Physiology. C. Rouiller, A. F. Muller, editors. Academic Press, Inc., New York. 3: 329-382. 